report by $\operatorname{Raz}$ et $a l,{ }^{1}$ on the clinical occurrence of stress incontinence in three women after medication with diphenylhydantoin for grand mal epilepsy. Using in-vitro techniques of measurement of the urethral pressure profile by the Brown and Wickham method on the urethra of the female dog, they proceeded to show a fall in the urethral pressure after administration of intravenous diphenylhydantoin. They gave intravenous noradrenaline, which produced a rise in urethral pressure but which was subsequently cancelled when diphenylhydantoin was administered. The suggested mode of action of diphenylhydantoin was to prevent the effective depolarisation of muscle cells, hence blocking the $\alpha$-adrenergic effect of noradrenaline.

I would like to point out one error in this article: the dose of propantheline was incorrectly stated as $15-200 \mathrm{mg}$ three times a day, whereas it should have read $15-20 \mathrm{mg}$ three times a day.

STUART L StantoN

Department of Obstetrics and

Gynaecology,
St George's Hospital Medical School,

London

${ }^{1}$ Raz, S, Zeigler, $M$, and Caine, $M$, Investigative Urology, 1973, 10, 293.

\section{Epilepsy in coeliac disease}

SIR,-Small children with coeliac disease (or otherwise ill-nourished) are prone to hypoglycaemia during periods of fever and anorexia and this is one trigger of febrile fits in infancy. Cerebral swelling at this time may cause temporal damage and later epilepsy. It would be interesting to know, perhaps from their mothers, how many of the epileptic patients of Dr R W G Chapman and his colleagues (22 July, p 250) had convulsions in their first two or three years of life.

T H Hughes-Davies

Central Hospital

Honiara,

Solomon Islands

\section{Length of hospital stay}

SIR,-The letters from Dr. D Phillips-Miles and $\mathrm{Mr} \mathrm{H}$ B J Chishick (17 June, p 1622) concerning the length of hospital stay of patients undergoing cataract surgery raise questions of unsatisfactory utilisation of beds. The mean length of hospital stay for such surgery in West Glamorgan in 1975 is variously stated to be six to 11 days depending on the surgeon (D Phillips-Miles) or 17 days for men and 25.4 days for women (H B J Chishick)

In Brookhaven Memorial Hospital during the first quarter of 197728 patients with cataracts were operated on, the average length of stay being $4 \cdot 2$ days. According to Professional Activities Study (PAS), which is a computerised hospital efficiency study used by hospitals throughout the United States, the average length of stay for cataract surgery from January to December 1975 was $5 \cdot 8$ days in the hospitals of the Eastern Region of the United States and 5.5 days in the whole of the United States.

All hospitals in the United States have utilisation committees, which supervise bed utilisation on a daily basis. Doctors whose patients stay longer than the expected norm must give a satisfactory explanation for the overstays. This is mandated by federal law.
Also Medicare (federal health insurance for the over-65 age group), Medicaid (federal-State health insurance for the indigent), and Blue Cross (non-profit voluntary hospital insurance) -which together cover $85 \%$ of hospital patients-will not pay hospitals for care unless it is considered medically indicated and cannot be rendered on an office or outpatient basis.

There have been repeated comments about poor utilisation in National Health Service hospitals. ${ }^{23}$ In some hospitals there is the will to be efficient, as in the outpatient herniotomy programme at the Royal Infirmary, Edinburgh. While much of medical care is determined by science and art, however, much more is determined by fashion. ${ }^{4}$ Examples of the influence of fashion are the therapeutic value of bed rest, which is questionable except in a very few circumstances; the use of aspirin, sleeping pills, and tranquillisers; and the difference in the length of hospital stay for the same condition in different communities.

The move to improved utilisation and efficiency must be encouraged to avoid the hotel aspect of early convalescence in hospital.

\section{G JACOBY}

President of medical staft

Douglas T Greaves

Utilisation Review Committee

Brookhaven Memorial Hospital,

Patchogue, ${ }^{1}$ Social Security Amendments of 1965, Title XVII, Printing Office, 1965 .

2 Jacoby, M G, Lancet, 1966, 1, 1366

Pearson, R J, et al, Lancet, 1968,2 .

Jacoby, M G, New York State fournal of Medicine, 1976, 76, 1504.

\section{Treatment of ulcerative colitis}

SIR,-We were interested by the letter of Dr A G Ironside and others (15 July, p 202) and agree that infectious diseases units have a contribution to make in the study of inflammatory bowel disease (IBD). We have studied patients with diarrhoea presenting to the infectious diseases unit at the City Hospital in Edinburgh $^{1}$ and have also encountered difficulties differentiating between IBD and infective colitis on the basis of the initial findings at sigmoidoscopy and rectal biopsy. Not only is this true of patients with specific intestinal infections but it also holds for those in whom no pathogen is isolated by routine methods-the very group of patients in whom IBD is most likely to be diagnosed mistakenly.

In our series 23 out of 36 patients with infective diarrhoea had negative stools and the diagnosis in these cases was made on clinical grounds. While some patients showed changes in the rectal mucosa similar to those reported in salmonellosis, ${ }^{2}$ a few showed changes highly suggestive of IBD. Thus the potential for misdiagnosis of infective colitis for IBD is not confined to patients suffering from infection with the recognised "mimics"-salmonella, shigella, and Entamoeba histolytica.

Surveys of prevalence of hypernatraemia

\begin{tabular}{ll|c|c|c|c}
\hline & & 1 Jan-31 December 1973 & 1 Oct 1975-30 Sept 1976 & 1 Jan-31 December 1977 \\
\cline { 2 - 4 } & Total admissions.. $\ldots$ &.. & 434 & 530 \\
No with hypernatraemia.. &. & $23^{*}$ & 11 & 5 \\
Deaths with hypernatraemia &.. & $2 \dagger$ & 1 & 1
\end{tabular}

*Three children had surgical disorders.

tOne died with intussusception, peritonitis, and hypernatraemic dehydration.
This observation has important implications. While it remains impossible for service laboratories to search routinely for the less easily identified enteric pathogens, it is important that the diagnosis of IBD, with all its long-term social and therapeutic implications, is not made prematurely in patients with non-specific diarrhoea and suggestive changes in the rectal mucosa. At the same time we would endorse your correspondents' view that acute colitis of whatever cause merits the closest attention.

We do not, however, agree that bowel infections should be regarded as part of the spectrum of IBD. The essential difference between these conditions is that bowe infections are usually self-limiting, although there are well-documented reports of IBD developing after infective episodes. If infective colitis and IBD are regarded separately and their differences defined then further information may be obtained about the host factors that predispose to the development of IBD and the role of infective episodes in its causation.

R J Dickinson

Gastroenterology Unit,
Leeds General Infirmary

Department of Pathology

D B L McClelland

Royal Infirmary,

Edinburgh

Dickinson, R J, Gilmour, $\mathrm{H} \mathrm{M}$, and McClelland, D B L, Gut. In press.

pathology, 1978, B K, and Morson, B M, Histo-

\section{Infant feeding practices}

SIR,-Drs Rosamond A K Jones and Elizabeth $M$ Belsey (8 July, $p$ 112) report a survey of infant feeding practices in a London borough. At the time of the survey (1975) unmodified milks were still widely used despite their high solute loads related to their sodium contents and the increased risks of excess solute load if such feeds are overconcentrated. The authors refer to observations made in our gastroenteritis unit, ${ }^{1}$ which showed a decline in hypernatraemic dehydration in children with gastroenteritis but persistence of the problem to some degree in infants fed on low solute milks. A more recent survey (see table) has shown a further substantial fall in the prevalence of hypernatraemia; furthermore, of those who had hypernatraemia only one child had a plasma sodium concentration above $160 \mathrm{mmol}(\mathrm{mEq}) / 1$-namely, $194 \mathrm{mmol} / \mathrm{l}$-and this child subsequently died.

It thus appears to be clear to us that there has been a dramatic and quite remarkable reduction in the incidence of hypernatraemia in infants with gastroenteritis admitted to our unit. We believe that this must be related to the abandonment of unmodified milks and the
H M GILMOUR

Regional Blood Transfusion Centre, 
warnings concerning overconcentration in the DHSS booklet Modern Infant Feeding Practices. The reduction in mortality and morbidity which this change has produced is a very welcome advance in preventive paediatrics.

P D MANUEL J A WALKER-SMITH Academic Department of Child Health, Lueen

${ }^{1}$ Whaley, P, and Walker-Smith, J A, Lancet, 1977, 1, 51.

\section{Audiometry in industry}

SIR,-We would appreciate the opportunity of commenting on your informative leading article (5 August, p 380) to clarify and expand our position on certain points which have been raised.

Referring to the Department of Employment code of practice, ${ }^{1}$ your article notes that the maximum permissible noise level for occupational exposure, 8 hours per day, of $90 \mathrm{~dB}(\mathrm{~A})$ "was designed to protect $99 \%$ of the exposed population from hearing loss induced by noise," and it could be inferred that this expectation was based on our work. ${ }^{2}$ We would like to comment on this statement.

While the precise meaning of the words "to protect $99^{\circ}$ " is not stated, our predictions would not give such an optimistic result on the basis of any recognised criterion of social adequacy of hearing (or conversely of hearing handicap) after a working life at this level of exposure. As an illustration, we assume age 60 , exposure duration 40 years, no hearing defect other than that due to noise, and the "low fence" audiometric criterion of the American Academy of Ophthalmology and Otolaryngology (AAOO). The latter, although obsolescent and unfavourable to our argument because of its lower connotation of handicap than later formulae, is taken because it would probably have been used in such assessments about the time of the issue of the code of practice and our report. ${ }^{12}$ In these conditions we would predict the proportion of hearinghandicapped persons at $11 \%$, not the undefined $1 \%$ implied in the article. In addition, the code does not state or imply that the level of $90 \mathrm{~dB}(\mathrm{~A})$ affords protection to $99 \%$ (or any other percentage) of those exposed. On the contrary, it emphasises that $90 \mathrm{~dB}(\mathrm{~A})$ is a maximum permissible level, not a desirable level, and that the attainment of lower values should be the aim.

Your leading article refers to the "warning" hearing levels in the Health and Safety Executive (HSE) audiometry document ${ }^{3}$ and contrasts them with the higher minimum values specified for compensation for occupational hearing loss by the AAOO, and the much higher arbitrary minimum values of the DHSS, administratively determined for the same purpose. The object of the warning hearing levels, which are age-related, is to identify individuals whose hearing levels, at their particular ages, already indicate a risk of sustaining a hearing handicap in later life and to take steps to avoid this occurrence. It is therefore to be expected that the warning hearing levels, especially for the younger age groups, will be much less than the hearing levels of persons eligible for consideration for compensation for an existing hearing defect.

Reverting to the question of the relations between noise exposure and the percentage of persons suffering a hearing handicap, this percentage is influenced by a number of factors. In addition to the basic quantitative relations between hearing loss and noise exposure, two secondary factors operate in any predictive calculations. These are (a) the frequencies and hearing levels of the audiometric criterion used to indicate hearing handicap, and $(b)$ the incidence in the noiseexposed population of raised hearing threshold levels not attributable to presbyacusis or to noise exposure. The time-honoured AAOO "low fence" is no longer generally accepted as a suitable index of social adequacy in cases where a hearing loss is of the sensorineural type, and it is now being replaced by other formulae. These include the average of the hearing levels at 1,2 , and $3 \mathrm{kHz}$, which is used by DHSS for compensation purposes. It is also used by the British Standards Institution (BSI) ${ }^{4}$ to define hearing handicap, which is taken to be present when this average is $30 \mathrm{~dB}$ or above. A recent study illustrates the operation of these two factors of hearing pathology and handicap criterion. An unselected population of elderly men in heavy industry, with an estimated average daily occupational noise level of about $87 \mathrm{db}(\mathrm{A})$ included no fewer than $37 \%$ in the handicap category by the BSI definition. A selected subgroup from the same population, believed to be substantially free from hearing deterioration other than that due to age and noise exposure, nevertheless yielded some $15^{\circ} \%$ in the handicap category.

We feel that this incidence of handicap should enjoin the greatest caution in establishing levels of noise exposure for regulatory purposes. Our data, from the outset, have ascribed an appreciable hazard to occupational noise when a daily acoustic immission of 90 $\mathrm{dB}(\mathrm{A})$ for 8 hours (or its equivalent on the equal-energy basis) is sustained repeatedly for a working lifetime. This is recognised in the recommendation of lower levels in the code of practice, ${ }^{1}$ and this attitude is strongly supported, we believe, by the various aspects noted above. These aspects surely compel the consideration of levels decisively below 90 $\mathrm{dB}(\mathrm{A})$ for any future noise regulations.

D W ROBINSON W BURNS

National Physical Laboratory, Teddington 1 Department of Employment, Code of Practice for
Reducing the Exposure of Employed Persons to Noise.

London, HMSO, 1972.
2 Burns, W, and Robinson, D W, Hearing and Noise in Burns, W, and Robinson, D W, Hear
Industry. London, HMSO,

Industry. London, HMSO, 1970. Audiometry in Industry Executive Working Group, British Standards Institution, Method of Test Estimating the Risk of Hearing Handicap Due to Noise Exposure, British Standard BS 5330 . London, BSI, 1976

${ }^{5}$ Burns, W, et al, Hearing Hazard from Occupational Noise: Observations on a Population from Heavy Industry, NPL Acoustics Report Ac80. Teddington,
National Physical Laboratory, 1977 .

\section{Amphi-}

SIR,-In your item "Words" (12 August, $p$ 488) the description given of an amphitheatre correctly describes a Greek or Roman theatre. Sir Bannister Fletcher in his enduring work on comparative architecture states that an amphitheatre "may be regarded as a compound of two theatres, stage to stage, thus making an auditorium round an elliptical arena." This definition brings out most clearly the meaning of the prefix amphi- as required by your contributor.

Marlborough, Wilts

F W HANFORD

\section{Maltese medical students}

SIR,-May I refer to my earlier appeal in these columns (10 September 1977, p 708) when we were trying to assist those Malta clinical students who wished to continue their studies in the United Kingdom?

Unfortunately the situation in Malta has in no way improved, and the students left at the medical school, who had started their medical studies before the beginning of the dispute, were given an ultimatum at the beginning of June that they should sign a contract with the Malta Government to engage in a revised medical course based on the student-worker concept. About half the students felt that they could not transfer to such a course, particularly as on its completion the degree would not be recognised internationally. It is hoped that these students will be able to find places in the United Kingdom medical schools to continue their studies, and so far 31 have been successfully placed. Many of the students, however, particularly those who have been asked by schools to repeat their second year, are concerned about the financial strain on their parents and relatives, who will be supporting them during this period.

May I therefore appeal to as many of our members as possible to help these students by sending a donation, however small, to the BMA Malta Fund?

J C CAMERoN

BMA House,

Tavistock
London

\section{Radiology work load}

SIR,-Another solution to the problem of radiological work loads, other than the one stated in the interesting article by $\mathrm{Dr} M \mathrm{~J}$ Brindle (12 August, p 514), would be to do what we already do to some extent here.

The $x$-ray rooms and equipment are, as it were, "let out" to the various clinical specialties. For instance the gynaecologists perform the hysterosalpingograms and much of the ultrasound, the gastroenterologists pancreatic investigations, vascular surgeons the angiography, the cardiologists the angiocardiography, the urologists the cystograms, etc. This could easily be extended, with the casualty officers and orthopaedic surgeons reporting the bone and joint radiographs, the gastroenterologists the barium studies (standard views taken by radiographers would miss very little), the urologists the excretion urograms, etc.

The fact is that the profession has come to see that the specialty of radiology is an artificial one, so named after one particular limited diagnostic technique, and that the advances of the future are likely to be simpler, cheaper, and safer for the patient. Most of the interesting and easier techniques have been taken away from radiology and future ones are unlikely to join it.

The lot of the diagnostic radiologist today is indeed a sad one: overworked, underpaid, of low status (often deserved), and with a dull professional life. Radiology should be disbanded and the work taken over by technicians acting under the guidance of the clinicians. 